\title{
Multi energy vector modelling of a Scottish Energy System: transitions and technology implications
}

Special Issue: Realising Transition Pathways

Elizabeth Robertson*, Institute of Energy and Environment, University of Strathclyde

Stuart Galloway, Institute of Energy and Environment, University of Strathclyde

* Corresponding Author info: Elizabeth Robertson, Institute for Energy \& Environment, University of Strathclyde, Technology and Innovation Centre, Level 4, 99 George Street, Glasgow, G1 1RD, United Kingdom (elizabeth.m.robertson@strath.ac.uk) 


\section{Abstract}

The Scottish Government's commitment for $100 \%$ of electricity consumed in Scotland to be from renewable, zero-carbon sources by 2020 continues to drive change in the energy system alongside European and UK targets. The growth of renewables in Scotland is being seen at many scales including industrial, domestic and community generation. In these latter two cases a transition from the current 'top down' energy distribution system to a newer approach is emerging. The work of this paper will look at a 'bottom up' view that sees community led distributed energy at its centre. This paper uses the modelling tool HESA to investigate high penetrations of Distributed Generation (DG) in the Angus Region of Scotland. Installations of DG will follow Thousand Flowers transition pathway trajectory ${ }^{1}$ which sees more than $50 \%$ of electricity demand being supplied by DG by 2050 . From this, insights around the technological and socio-political feasibility, consequences and implications of high penetrations of DG in the UK energy system are presented. Results demonstrate the influence that system change will have on regional and local emission levels under four separate scenarios. It is shown that the penetration of DG requires supplementary installations of reliable and long term storage alongside utilisation of transmission and transportation infrastructures to maximise the potential of distributed generation and maximise whole system benefits. Importantly, there must be a level of co-ordination and support to realise a shift to a highly distributed energy future to ensure there is a strong economic case with a reliable policy backing.

\section{Keywords}

- Distributed Generation

- Energy policies

- Multiple Energy Vector Modelling

- Energy System Scenarios 


\section{Introduction}

As the UK aims to achieve a transition to a low carbon energy system by 2050 , whilst maintaining security of supply and affordability of energy service, there are many barriers that arise from technical, societal, environmental and economic aspects that will need to be overcome. Recent work by the authors and colleagues has explored transition pathways for the UK energy system to 2050 under different governance arrangements ${ }^{1}$ and the generation and network infrastructure requirements under these pathways ${ }^{2}$. Particular challenges highlighted are how to facilitate the nation's change in energy use habits, the introduction and use of CCS, the widespread integration of storage, non-conventional gas and the increasing reliance on renewable generation. Changes to system design and operation, and challenges to the norms, arise from policies, drivers and investments at international, national, regional and local levels.

As the UK system transitions to a more sustainable energy system, that continues to provide secure, affordable and low-carbon energy services, new energy vectors are introduced, such as $\mathrm{CO}_{2}$ emerging as a tradable and transportable commodity and non-conventional gas displacing use of natural gas in the system. The introduction of new energy vectors in the UK system requires the application of methods that account for their interdependences and the roles and interactions of the actors who participate within the network. Assessing these interdependencies is particularly important given recent UK energy policy announcements that place a new emphasis on gas-fired electricity generation, alongside new renewables and nuclear generation ${ }^{3}$. The future of national electricity and gas grids must be reconciled with a transition to a low carbon energy system that could include significantly higher proportion of distributed generation (DG), as well as new end use technologies for heat provision such as electric heating - this requires tools for whole systems energy analysis.

Scotland has surged ahead of the rest of the UK setting its own renewable energy targets that reach further than UK government targets set out in the Climate Change Act ${ }^{4}$. The Scottish Government targets aim to meet the equivalent of $100 \%$ of the demand for electricity from renewable energy by 2020 with an interim target of $50 \%$ by $2015^{5}$. The 2015 target was met nearly a year ahead of schedule with the equivalent of $49.8 \%$ of Scotland's electricity consumption in 2014 coming from renewable generation ${ }^{6}$. Scotland has a concentration of renewable resources in the UK, and has some of the highest potential of renewable generation in Europe ${ }^{7}$. Therefore, the deployment potential of renewable electricity generation (including that of distributed generation) is high, with an ambition of the Scottish Government "to see more householders, public sector organisations and businesses 
generating their own energy from micro-renewables, moving the technology from a niche market to the mainstream" 5 .

It is therefore necessary to investigate the feasibility, and implications, of high penetrations of distributed generation in Scotland. National drivers and objectives will impact local and regional energy systems and encourage, or demand, system change either in design or operation. It needs to be established therefore what upgrades to existing infrastructures are necessary and what, if any, new infrastructures must be introduced as a result of a shift of system objectives and constraints.

In order to model the transition of Scotland to 2050 and a lower carbon system, with a higher share of generation coming from renewables and a greater share of generation from distributed sources, a trajectory for change must be established. This work will draw on the socio-technical scenarios work of the Transition Pathways and Realising Transition Pathways EPSRC consortia ${ }^{8}$ and specifically the Thousand Flowers Pathway for UK energy system transition. The Transition Pathways consortium developed three 'transition pathways' - classed as sociotechnical storylines and derived from a social and engineering analysis of key actors in the energy system ${ }^{9,10}$. The three transition pathways describe plausible evolutions of the UK toward a low carbon economy to 2050 for the UK's transition to 2050 and a lower carbon economy ${ }^{1,2,11,12}$. In the Thousand Flowers transition pathway there is a diversity of local, bottom-up, drive from individuals, community groups and local authorities who encourage system change by becoming active participants in the energy system. This range of local energy solutions challenges the dominance of large energy companies and sees, by 2050 , more than $50 \%$ of demand being fulfilled by distributed generation. The necessary technical and institutional transformation necessary to move from a centralised system to this highly distributed energy future of the Thousand Flowers Transition Pathway was completed by the Realising Transition Pathway Consortium ${ }^{13}$. The Scottish Government's targets for the penetration of renewables and local energy projects ${ }^{6}$ aligns with the Thousand Flower scenario hence the multiple energy system analysis of a Scottish system transition in this paper will be done in the context of a of the Thousand Flowers transition pathway.

This paper will begin by introducing the modelling approach for this work - the HESA tool. Following there is a description of the Scottish energy system being modelled - the Angus region - and a discussion of parameters used in simulations. The paper closes by first presenting a discussion of the results of simulations before drawing conclusions. 


\section{Modelling Approach}

In order to examine the implications of a greater penetration of renewables and DG in Scotland, the Thousand Flowers Pathway is used as context for modelling the Angus region in the East of Scotland. A regional - rather than national - study was utilised in the work described in this paper as the dominance distributed generation in the pathway meant that a higher resolution, than a national model would allow, was necessary. The HESA (Hybrid Energy System Analysis) tool ${ }^{14,15}$, is used to investigate costs and implications to energy flows in the Angus region using a multiple energy vector model to identify feasible energy systems.

Taking a system view across multiple energy vectors allows for the examination of integrated systems as they move toward a low carbon economy ${ }^{16-21}$. Where the physical infrastructure of different energy vector systems meet, for example gas-fired power stations or mixed-demand centres, there is already joint working taking place (necessary in both planning and operation). HESA exploits this joint working procedure between sectors to coordinate future infrastructure installations and reinforcements while working for a common goal thus representing more 'horizontally integrated energy companies' 22 that work across more traditional energy company boundaries (and their principal vectors). The HESA tool facilitates the investigation of feasible future energy infrastructure designs when different energy vector systems (i.e. electricity, natural gas and solid fuels etc) undertake coordinated and collaborative system planning and operation to lower overall system costs (either to themselves, the customers or other objective).

This linking of energy vector infrastructures creates flexibility and provides an opportunity for a new way of planning energy systems and dispatching energy along different energy vector streams ${ }^{16,17}$. Examples of 'whole energy system' research in the literature such as Hammond et al. ${ }^{23}$ analyses historical data regarding the UK's energy usage across multiple energy carriers to determine the adjustments to the infrastructure to accommodate changes in consumption habits from 1965 to 2000. A combined model of the American gas and electricity networks were used to predict movement in nodal pricing ${ }^{17,18}$ through use of past data sets, but was a model of economic transitions rather than necessary physical improvements to the system.

HESA brings together the use of several successful methods in the literature including a modular framework used by Bakken and Holen ${ }^{16}$ where separate components represent transport, generation and storage elements. The Energy Hub technique, developed at ETH Zurich ${ }^{24}$, is used in multiple studies ${ }^{19-21,24}$ and is a mathematical 
formulation for system component representation that incorporates the relationships between different energy carriers for use in modelling and optimizing coupled energy systems such as national energy networks.

Energy hubs are interfaces where a number of energy inputs from an external system are connected to loads through a set of energy convertors. A hub is able to represent conversion of energy between different energy vectors, for example the conversion of energy from natural gas into heat and electricity by a CHP unit. Simpler conversions through electric transformers or heat exchangers and integrated storage elements are also possible. One energy hub is able to represent a geographical collection of convertors, storage capacity and direct transportation, and can represent components on the scale of a dwelling, community, town or even a country. In this way, energy hubs are able to act as Virtual Power Plants ${ }^{25,26 .}$

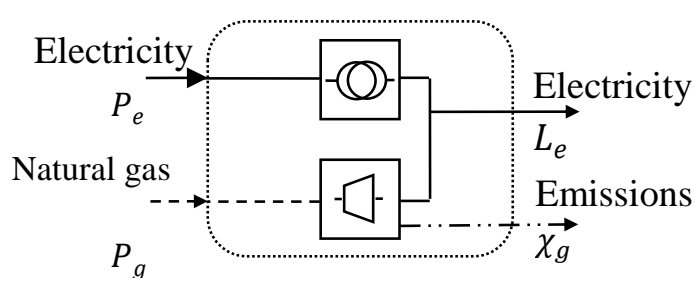

Figure 1 A simple 2-component, 3-vector energy hub

The hub in Figure 1 is an example of a simple configuration with only direct electrical transmission and a gas turbine. The inputs of electricity and natural gas, to the hub are defined as $P_{e}$ and $P_{g}$ respectively, the electricity output $L_{e}$ with the emissions due to the gas turbine $\chi_{g}$. All components of a hub have a coupling factor assigned to the technology and here are assigned as to the efficiency of the electrical transmission, $\eta_{e e}^{T}$, (which can be used to incorporate losses) and the fuel efficiency of the gas turbine, $\eta_{g e}^{G T}$. The electricity output of the simple hub is calculated through the use of the component coupling factors as follows

$$
L_{e}=\eta_{e e}^{T} P_{e}+\eta_{g e}^{G T} P_{g}
$$

Equation 1

Emissions from the gas turbine are calculated based on the quantity of fuel throughput by use of the emission factor $C_{g e}^{G T(p r e)}$ to determine total emission output:

$$
\chi_{g}=C_{g e}^{G T(p r e)} P_{g}
$$

Combining Equation 1and Equation 2 gives: 


$$
\left[\begin{array}{l}
L_{e} \\
\chi_{g}
\end{array}\right]=\left[\begin{array}{cc}
\eta_{e e}^{T} & \eta_{g e}^{G T} \\
0 & C_{g e}^{G T}(p r e)
\end{array}\right]\left[\begin{array}{l}
P_{e} \\
P_{g}
\end{array}\right]
$$

Equation 3 can be simplified to a form with the hub output vector $\boldsymbol{L}$ related to the hub's input vector $\boldsymbol{P}$ by the conversion matrix as follows:

$$
\boldsymbol{L}=\boldsymbol{C P}
$$

Equation 4

With inputs $\boldsymbol{P}_{\boldsymbol{i}}$ and outputs $\boldsymbol{L}_{\boldsymbol{i}}$ the ith hub, $\mathrm{H}_{i}$, becomes a component module of a larger system representation - a Node - as seen in Figure 2. Nodes are used in the modelling to represent the generation, demand, storage and transmission and transportation capability and capacity of a geographical area.A number of nodes are connected via transportation and transmission networks for the modelling of conversion and transportation of multiple energy vectors. Figure 2 illustrates such an arrangement for a node, Node $\alpha$, and the connection of components and the flow of energy vectors from its associate hub, storage and demand components (labelled $i$ ).

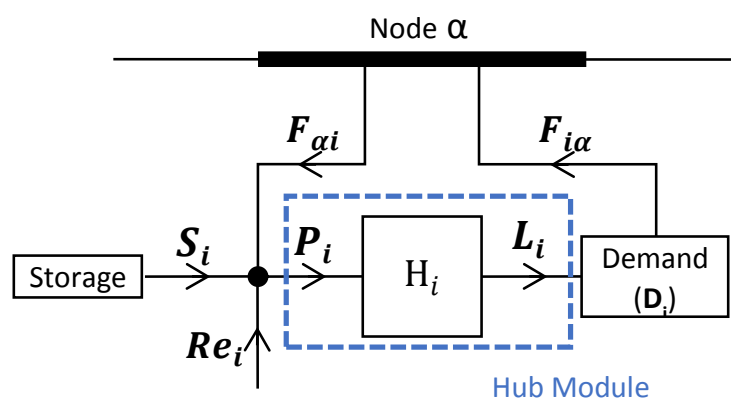

Figure 2 An energy hub with renewable energy sources $\left(R e_{i}\right)$. The hub is connected to a system with local storage.

Figure 2 demonstrates the integration of non-dispatchable renewable energy sources $\left(\boldsymbol{R} \boldsymbol{e}_{\boldsymbol{i}}\right)$ and storage capacity $\left(\boldsymbol{S}_{\boldsymbol{i}}\right)$ with a hub model $\left(\mathrm{H}_{i}\right)$ and its representation of dispatchable generation and transmission throughput. Formulaic representation is such that the input vector $\left(\boldsymbol{P}_{i}\right)$ for the hub $H_{i}$ is the sum of the energy import from the rest of system $\left(\boldsymbol{F}_{\alpha i}\right)$, the storage dispatched to the hub $\left(\boldsymbol{S}_{i}\right)$ and the renewable energy sources at the hub $\left(\boldsymbol{R} \boldsymbol{e}_{\boldsymbol{i}}\right)$. Such that:

$$
P_{i}=F_{\alpha i}+S_{i}+R e_{i}
$$

Equation 5

The formulations of individual hubs and nodes in a system are optimised to find a least cost solution for the generation/provision of energy. Following on from dispatch HESA identifies feasible, and least cost, 
transportation solutions using network flow programming ${ }^{17,18}$, a technique that is computationally "much faster than linear programming since network flow can be viewed as a special linear programming problem" 27.

The electrical connections between zones will not be modelled in terms of resistance, inductance or impedance of lines and neither will natural gas lines be examined for density and temperature limitations. Instead, system specification will limit the flow or rate of flow through connections, progressing further to describe the losses that will occur in the transfer. In this way, bulk transfers are considered and shortfalls in transfers will inform necessary reinforcements to support the particular generation and demand regimes as defined by the transition pathways

The system wide transportation and transmission problem takes the description of the multiple energy networks together with the net export or import of each of the hubs for each energy vector as inputs to an optimisation problem. Optimisation is used to find a least cost solution (i.e. generation levels, storage dispatch and transportation) so that the total system will be balanced such that no one hub is either in net deficit or excess of any vector by creating flows across the necessary lines in such a way that total system costs are minimised.

The objective cost for HESA optimisation problem can be determined according to a varied number of aims for example:

- Minimising the total cost to the system operators/maximising their profit margins;

- Minimising the use of the networks and therefore operating similarly to the principle of reducing food miles ${ }^{28}$ and using what is produced locally;

- $\quad$ Minimising the total cost of energy to the end user;

- Minimising the cost or number of reinforcements to the network; or

- Minimising the total carbon emissions.

It is very important that the cost objective of any problem is properly considered and formulated. Other research that has utilized energy hubs have included maximising revenue for generators that have taken part in system balancing ${ }^{29}$, minimising the total cost of 'raw' energy needed for generation and end use ${ }^{30}$, and minimising the cost of energy needing to be injected into a system ${ }^{31}$.

For the examination of the Thousand Flowers transition pathway we will examine the Angus region of Scotland which has clusters of population, a distribution of renewable energy resources and a connecting electrical and gas network. Simulations will be run over multiple system objectives to determine the impact of objectives and drivers for transition. The following section provides more details on the regional simulation studies. 


\section{Simulations}

The HESA simulation tool was used to examine the Angus region of Scotland which is identified in the context of a map of Scotland in Figure 3a. Angus is a region that lies of the East coast of Scotland and borders Aberdeenshire, Perth and Kinross, and Dundee City but with electrical connections to Perth and Kinross and Dundee City only. The six population centres of Arbroath, Brechin, Carnoustie, Forfar, Kirriemuir and Montrose are all shown in Figure $3 \mathrm{~b}$ as well as the electrical connections in the region. The Angus region of Scotland was chosen as the model for simulations as it has a range of population centres including urban, suburban and rural representing the mixed nature of demand in Scotland. Secondly, the region is not islanded with electricity and gas grids which are both non-constrained, resilient and connected to the greater UK national networks. Choosing the Angus region as a model allows for the examination of regional network operation in Scotland under multiple system objectives without severe network constraints affecting results.

(a)
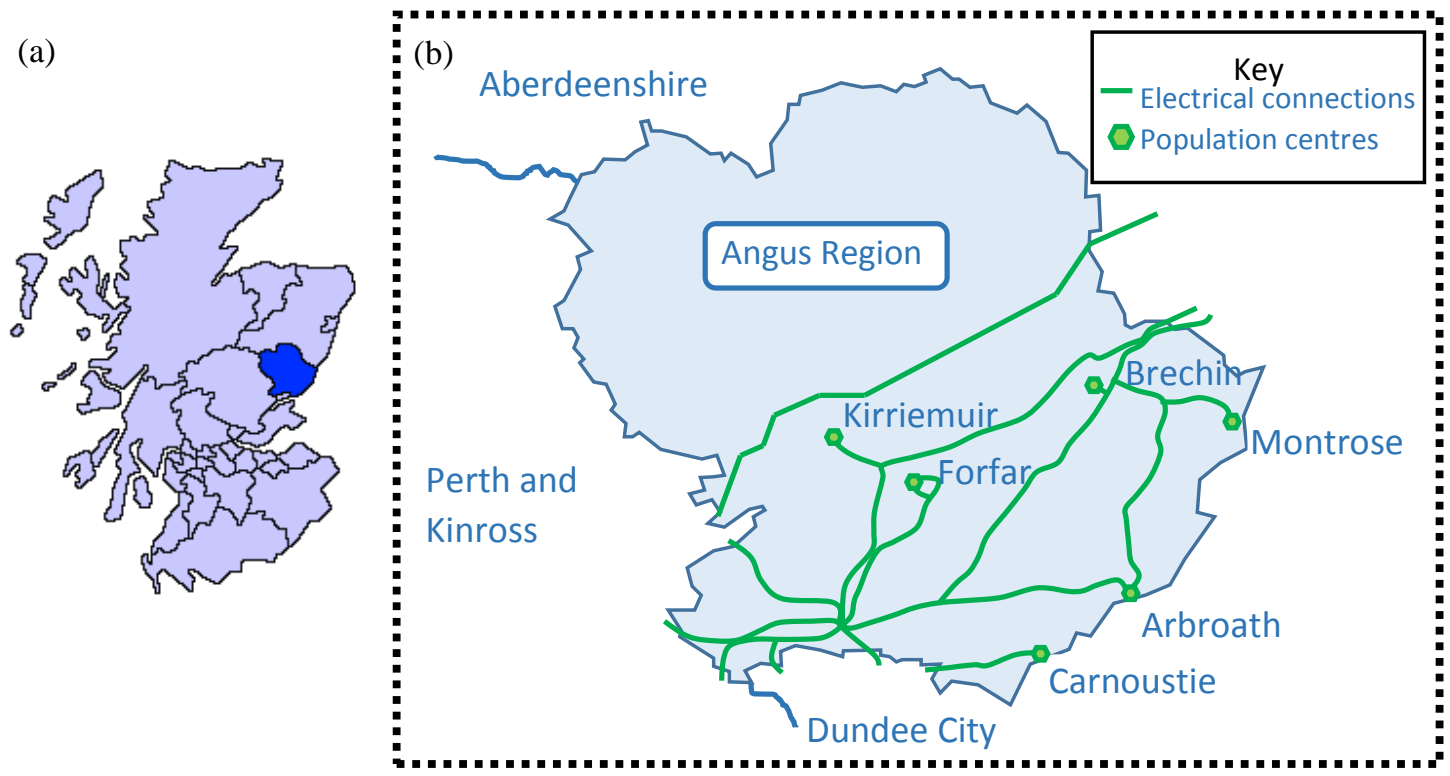

Figure 3a\&b - The location of Angus in Scotland and a map of the network and the interaction of load centres within the Angus.

The Angus region was analysed using the HESA simulation tool to determine the applicability of different technologies (namely Solar PV, micro-wind and CHP units) in the region to meet different system objectives. A simulation was carried out of the Angus region model in 2050 with no DG installed so there existed a baseline for comparison. Further simulations were then completed following a trajectory for the installation of DG technology as laid out in the Thousand Flowers transition pathway ${ }^{1,2}$. Some data used in this analysis was drawn from the 
DECC 2050 Pathway Calculator ${ }^{32}$ which had been calibrated to fit Thousand Flowers in 2050 to ensure accuracy.

A description of the Angus region model and simulation parameters now follows.

\section{The Angus Region model}

A representative model of the Angus region was generated for the purpose of running simulations using the HESA tool. The model of the region included the electrical and gas networks that couple high population density areas, local energy demands of heat, electricity and natural gas, distributed energy resources and representations of grid electrical and natural gas supply. Line lengths and capacities of the electrical and natural gas network were drawn from system operator data ${ }^{33,34}$ and a schematic of the electrical grid connectivity is presented in Figure 4.

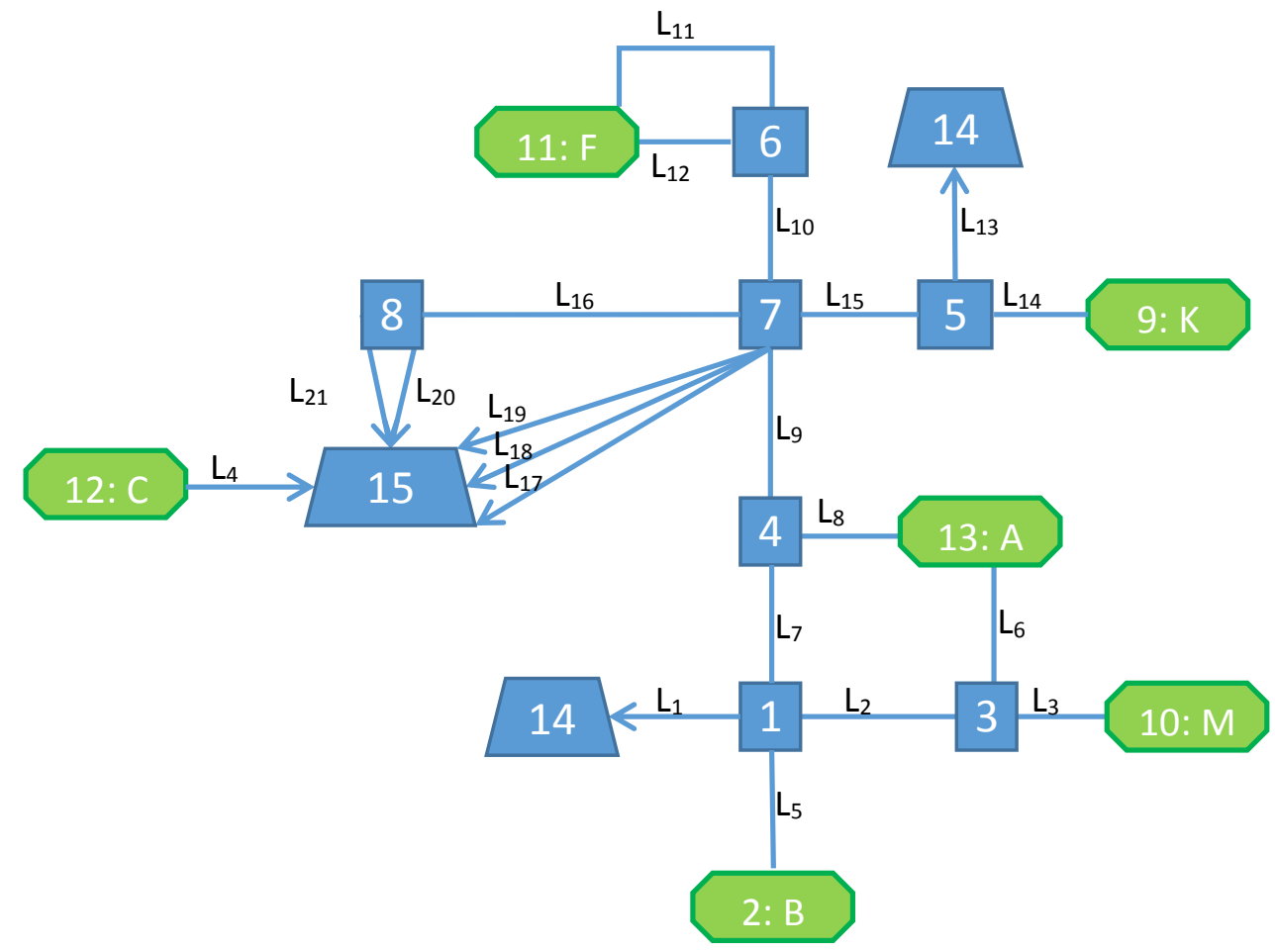

Figure 4 - A representation of the network and load centres structure of the Angus. All nodes have an assigned numeric label as for node $\alpha$ in figure 2, load centres are represented as hexagons, connections to the UK grid trapezoids and connector (or branch) nodes as squares. All lines are numbered with the convention $L_{j} \cdot$

2050 demand data for the six high density population areas was generated utilizing both national DECC data ${ }^{35}$ and regional census ${ }^{36}$ data. Demand data was drawn from the DECC pathways analysis with level representative of the Thousand Flowers transition pathway with a low average house temperature and the highest thermal efficiency levels. Average household electricity consumption in 2050 was consequently $1,388 \mathrm{kWh}$ per annum and gas consumption $181 \mathrm{kWh}$ per annum. Heat demand was calculated separately from these figures due to the inclusion of the heat energy vector in the model allowing for separate representation. 
2001 Census data was used to determine the number of dwellings in the Angus region's population centres alongside occupancy levels and thus determine the energy demand of each of the population centres. Census data was also utilized to determine the maximum levels of solar photovoltaics and micro-wind turbines installations as per the per person and per dwelling statistics in the DECC 2050 Pathway Analysis ${ }^{35}$. This work led to the Angus region model data as in Table 1.

\begin{tabular}{|l|l|l|l|l|l|l|}
\hline Zone & 2 & 9 & 10 & 11 & 12 & 13 \\
\hline Town Name & Brechin & Kirriemuir & Montrose & Forfar & Carnoustie & Arbroath \\
\hline No of dwellings & 3,722 & 2,759 & 5,499 & 6,134 & 4,472 & 10,887 \\
\hline $\begin{array}{l}\text { Max wind install } \\
(\mathrm{kW})\end{array}$ & 18,610 & 13,795 & 27,495 & 30,670 & 22,360 & 54,435 \\
\hline $\begin{array}{l}\text { Max solar install } \\
\text { (kW) }\end{array}$ & 41,337 & 29,522 & 60,566 & 69,292 & 56,635 & 127,872 \\
\hline $\begin{array}{l}\text { Electricity Demand } \\
\text { (MWh/annum) }\end{array}$ & 5,167 & 3,830 & 7,634 & 8,515 & 6,208 & 15,114 \\
\hline $\begin{array}{l}\text { Natural gas } \\
\text { Demand } \\
\text { (MWh/annum) }\end{array}$ & 673 & 499 & 995 & 1,110 & 809 & 1,970 \\
\hline $\begin{array}{l}\text { Heat Demand } \\
\text { (MWh/annum) }\end{array}$ & 31,495 & 23,346 & 46,532 & 51,906 & 37,842 & 92,126 \\
\hline
\end{tabular}

Table 1- 2050 Demand and generation statistics of Angus population centres

Alongside local distributed generation within the population centres there are network connections to other regions meaning that supplementary energy supply (multiple vectors) can be drawn from other nodes to satisfy demand. Similarly, surplus generation (multiple vectors) can be can be exported to the rest of the grid. This can be done to the North or the South via nodes 14 and 15 respectively as seen in Figure 4.

\section{Simulation parameters}

A 'baseline' simulation was run with no distributed generation installed on the grid. Similarly, there was no natural gas CHP units installed, with all heating being from traditional gas boilers instead. This 'baseline' simulation was run with the objective to minimize the total cost of energy to the consumer (which includes generation and transport costs). In contrast to this baseline, a series of simulations were run that represent distributed generation installation rates of the Thousand Flowers pathway. This trajectory has an install of $5.4 \mathrm{~m}^{2}$ of solar photovoltaic panels per resident and $5 \mathrm{~kW}$ of wind per household alongside $40 \%$ of properties transitioned to natural gas CHP for space and hot water heating. A summary of the trajectories can be seen in Table 2 .

\begin{tabular}{|l|l|l|l|l|}
\hline Trajectory & Gas CHP & Gas Boiler & Wind & PV \\
\hline Baseline & $100 \%$ & $0 \%$ & None & None \\
\hline
\end{tabular}




\begin{tabular}{|l|l|l|l|l|}
\hline Thousand Flowers & $40 \%$ & $60 \%$ & $\begin{array}{l}5 \mathrm{~kW} \text { per } \\
\text { household }\end{array}$ & $5.4 \mathrm{~m}^{2}$ per resident \\
\hline
\end{tabular}

Table 2 A Summary of technology installations in the different trajectories

Throughout all simulations of 2050 trajectories, costs and incomes are generated from 2015 data and have not been adjusted to a 2050 economic model. Similarly, demand and generation data and emissions ratings are based on existing 2015 technologies and there is no projection of efficiency changes out to 2050. Although there are methods in the literature for forecasting electricity prices ${ }^{37}$ and projecting domestic demand using, for example a MARKEL model ${ }^{38,39}$ such activities are out with the purview of the works in this paper and beyond its limitations. However, as all figures and sources are consistent across all simulations comparisons can be made between them and analysis completed of the impacts of different objections and constraints and then conclusions drawn.

The simulations presented in this paper of the analysis of the Angus region use the energy hub for representation of technology options as seen in Figure 5. This is a versatile and complex 7-component, 5- energy vector hub model, designed for HESA, as 'multi-purpose' and 'fully adaptable' such that the hub is universal across the system. The energy hub is used to represent the distributed generation and transmission capabilities of a singular population centre. The hub that is used in this analysis contains four generation components - conventional gas boilers, gas fired CHP, wind, solar - as well as transmission capabilities for electricity, natural gas and heat (useful if district heating is to be considered).
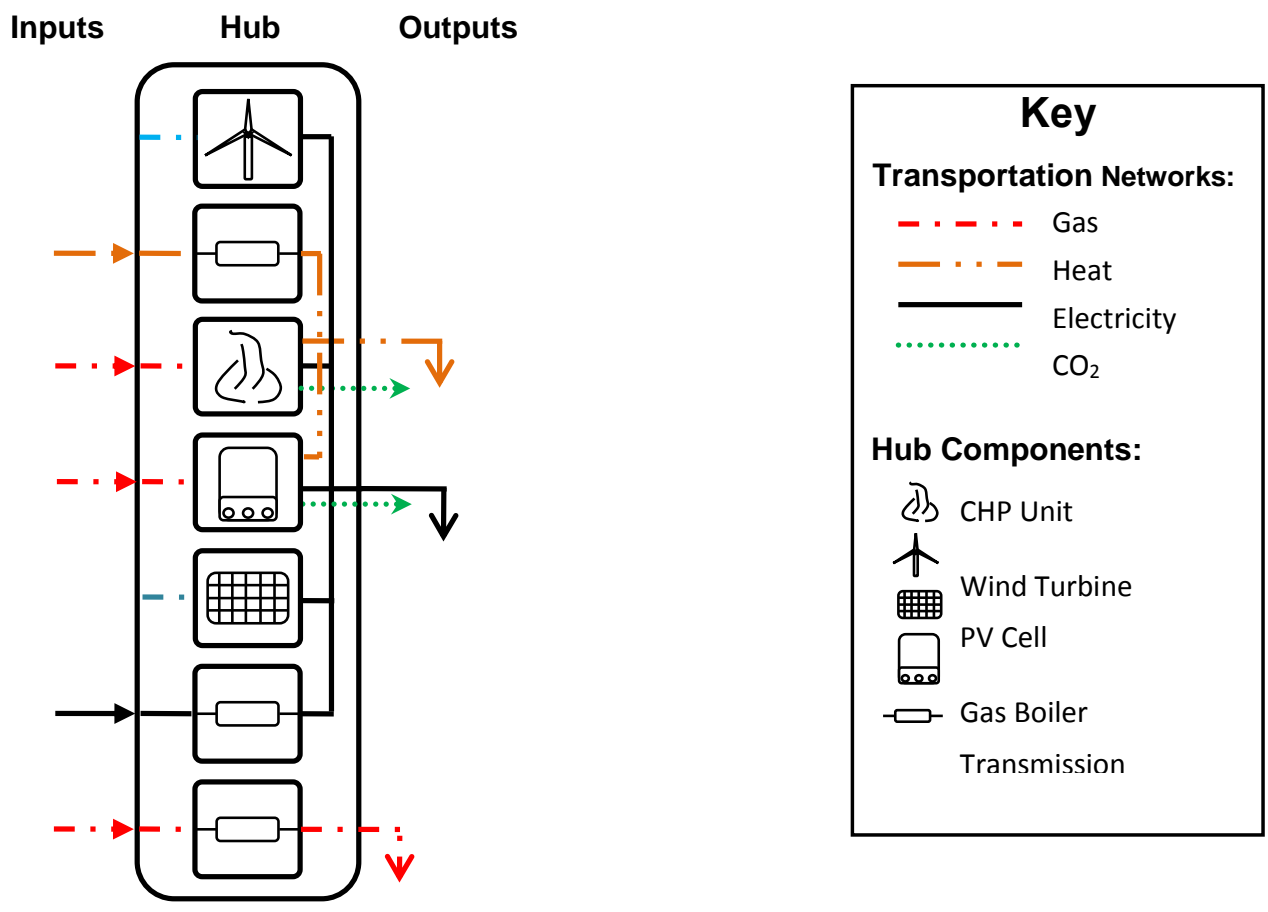

Figure 5- Regional system analysis energy hub 


\section{Results and Discussion}

The summary results of simulations of a 2050 view of the Angus region (labelled S-1 to S-4) are shown in Table 3 under a variety of objectives (either minimizing carbon dioxide emissions or costs to the consumers) and level of constraint on the network. As a condition of the simulations all demand (across the multiple vectors) is met through dispatch of local and grid generators and supply and a feasible energy transport solution found. Cost of energy to the consumers was calculated by a function of the costs of importing natural gas and electricity and the revenue received from local generation by way of Feed in Tariffs and export tariffs ${ }^{40}$.

\begin{tabular}{|c|c|c|c|c|}
\hline Simulation & $S-1$ & $S-2$ & $S-3$ & $S-4$ \\
\hline Trajectory & Baseline & $\begin{array}{l}\text { Thousand } \\
\text { Flowers }\end{array}$ & $\begin{array}{l}\text { Thousand } \\
\text { Flowers }\end{array}$ & $\begin{array}{l}\text { Thousand } \\
\text { Flowers }\end{array}$ \\
\hline Objective & $£$ & $£$ & $\mathrm{~kg} \mathrm{CO} 2$ & $£$ \\
\hline Network constrained & No & No & No & Yes \\
\hline Population Centre & \multicolumn{4}{|c|}{ Yearly Electrical Surplus (MWh) } \\
\hline 2: Brechin & $-5,167$ & 36,749 & 2,732 & -311 \\
\hline 9:Kirriemuir & $-3,830$ & 32,583 & 597 & $-1,047$ \\
\hline 10: Montrose & $-7,634$ & 40,193 & 6,177 & 1,734 \\
\hline 11:Forfar & $-8,516$ & 41,781 & 7,765 & 2,680 \\
\hline 12: Carnoustie & $-6,208$ & 39,586 & 5,570 & 2,090 \\
\hline 13: Arbroath & $-15,114$ & 87,289 & 54,979 & 8,513 \\
\hline \multicolumn{5}{|c|}{ Total System Statistics } \\
\hline $\begin{array}{l}\text { Net Electrical Import/Export } \\
\text { (MWh) }\end{array}$ & $\begin{array}{l}\text { Import } \\
(46,470)\end{array}$ & $\begin{array}{l}\text { Export } \\
(-278,180)\end{array}$ & $\begin{array}{l}\text { Export } \\
(-77,820)\end{array}$ & $\begin{array}{l}\text { Export } \\
(-13,659)\end{array}$ \\
\hline Direct emissions $\left(\mathrm{kg} \mathrm{CO}_{2}\right)$ & 60,622 & 62,411 & 62,411 & 62,411 \\
\hline Approx. revenue ( per household) & $-£ 663$ & $£ 2,331$ & $£ 899$ & $£ 392$ \\
\hline
\end{tabular}

Table 3 - Angus simulation results with electrical and emissions data

The simulation S-1 is the 'baseline' 2050 trajectory with no distributed generation and is reflective of a 'businesses as usual' pattern and is a base for comparison of the other studies. As such, in the case of S-4, the constrained network study, the maximum network capacity was set to the S-1 network capacity $(+10 \%)$ as the investment necessary for S-1 would take place even without DER deployment thus that network is taken as the benchmark. 


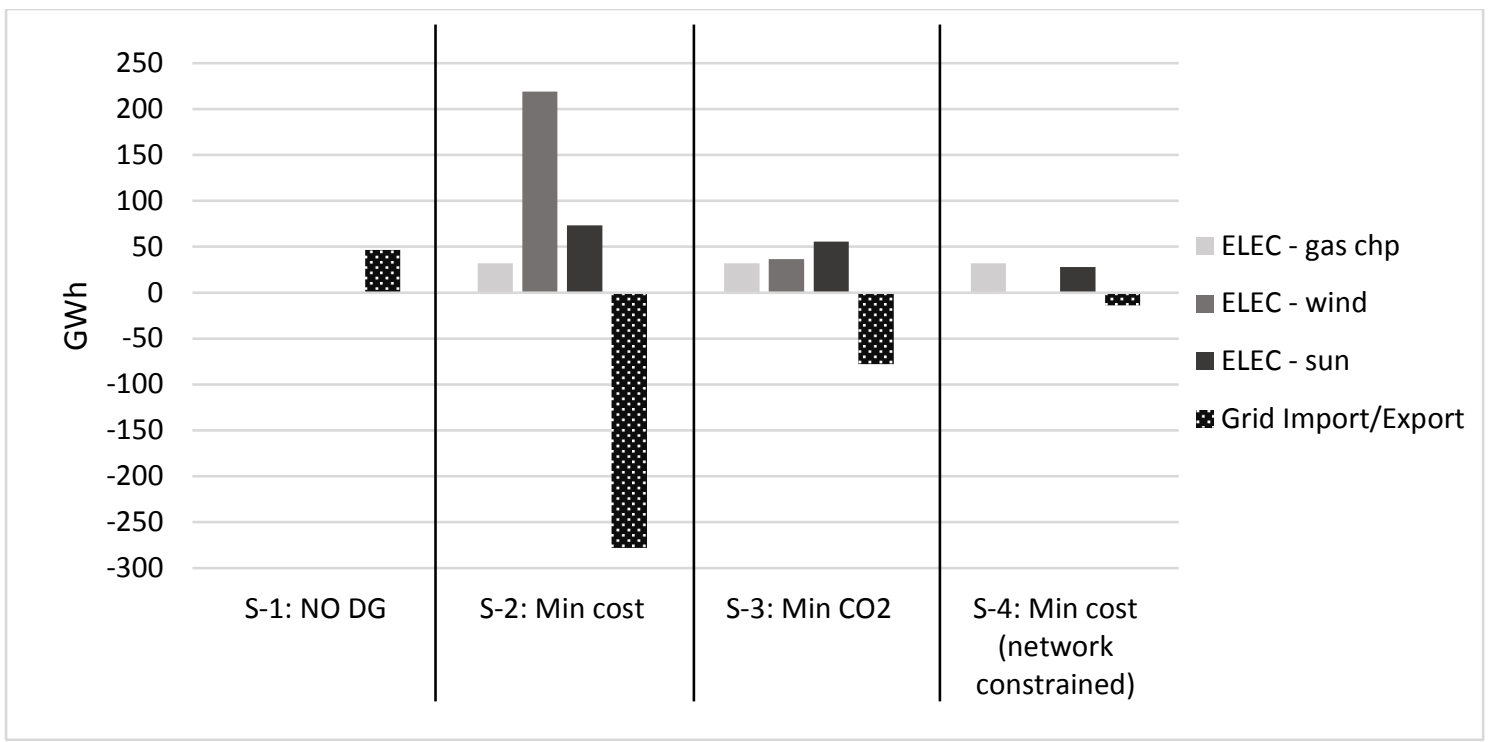

Figure 6 - Generation and export/import comparisons of the Angus simulations

The objective of system operation produces noticeable differences to the utilization (and therefore necessary installation of) distributed generation as seen in Figure 6. In an unconstrained network simulation when there is no financial force but rather a drive to minimise emissions, as in S-3, there is no compulsion to produce more generation than is necessary. This is in comparison to $\mathrm{S}-2$ where an objective to minimize cost to (and maximize revenue of) households sees very high levels of electrical generation from distributed sources and very high net annual export. Total local annual electrical generation in this $\mathrm{S}-2$ is $325 \mathrm{GWh}$ with a net export from Angus in the year of $278 \mathrm{GWh}$. However, in S-3 we see a markedly less significant level of local generation totally just 124 GWh in 2050 and a net export of $77.8 \mathrm{GWh}$ which reduces the impact on the network.

Therefore, an emissions objective creates a very different picture of electrical generation in Angus than when considering monetary gain, however as can be seen in Table 2 direct emissions levels are consistent throughout the four simulations. This is due to the boundaries of the model including only the direct emissions of Angus from production and consumption of energy (natural gas, heat and electricity) - and not considering the export of local low carbon electricity benefitting neighbouring regions and the savings in emissions that would be then created elsewhere.

The emissions levels are constant across the three Thousand Flowers trajectory simulations as all emissions in S2 to S-4 are coming from the same source - heat generation by way of gas fired CHP and more conventional boilers. To reduce these emissions efficient and renewable (zero carbon) technologies must be found to heat domestic dwellings. Biomass is a low carbon option but research shows that there are many challenges in with 
regard to limited space and suitability of crops for growth [16] as well the 'low carbon' title given to biomass being challenged [17].

Comparing the electrical surplus results for the population centres in the Angus region between S-4 and S-2 (the constrained and unconstrained simulations) in which both have cost as an objective function sees that a constrained network, although still allowing all demand to be met my electricity from DER sources, DER is highly underutilised. Even utilising the availability of local electrical storage units the output from DG is curtailed meaning that total electrical export from the constrained system in S-4 is less than 5\% of that in S-2 and the financial revenue is less than half that in S-2. This means that a constrained network and lack of financial investment beyond a 'business as usual' case will prevent the full utilisation of DER and the economic benefits that they can bring.

Finally, we can see that simulation S-4, in a 2050 with a heavily constrained network, with an objective to minimize cost (maximize revenue) which had driven up local generation in S-2, generation is heavily constrained. Annual local generation is only $60 \mathrm{GWh}$ and total grid export $14 \mathrm{GWh}$. Therefore, if we are to have any meaningful levels of distributed generation installed it is essential to reinforce the grid beyond 'business as usual' levels.

To minimise the carbon intensity of electricity used domestically it is essential that the most is made of the zerodirect-emissions from domestically installed DG. In modelling simulations S-2 to S-4 all contained the capability to store electric locally, with high efficiencies for long periods, hence the ability to stay 'off grid'. It is therefore important that affordable storage units for a local scale are available. This requires financial backing and clear revenue streams for market entrants but will enable carbon free energy from DG to be produced locally and stored when (natural) resources are not available (i.e. a calm night when neither wind or solar generation can generate). Local electrical storage, as well as an increased capacity in the networks, is therefore essential to minimising emissions from dwellings as well as generating maximum value from DG for communities and other stakeholders.

Looking across the simulations studies considered what is demonstrated is that local drivers will affect local change. Especially in the case of minimising emissions in simulation S-3, it is seen that a drive to minimise local emissions will do just that, minimise the emissions within a boundary. However, as the UK energy system is operated nationally, and emission targets are national, there is a need for areas with abundant renewable resources, such as Angus and those like it, to over-produce 'green energy' for export with consumption elsewhere. Specifically in areas where renewable sources are scarce. This type of approach would require a coordinated national scale energy system plan to enable the costs of installation of generation to produce electricity and electrical storage to stabilise intermittency, and the mismatch of demand and supply curves, to be shared. 
Similarly, the benefits to a national system from local, distributed, action must also be shared whether they be monetary, emissions savings or otherwise.

A lack of clarity for the future of the energy system means uncertainty for investors, for R\&D in and installation of distributed generation, storage and associated transmission and transportation network reinforcements. In the case of a system with a high penetration of DG there needs to be regional planning - on a level similar to that of the Angus model - so that the geographic and societal specifics of an area can be best understood and realised. National co-ordination and harmonisation is needed for energy system change (where applicable) along with a wider sharing of knowledge, burdens and benefits, that can also be distributed. In the Distributing Power Report

${ }^{41}$ the Realising Transition Pathways consortium offered an architecture of support for coordinating and supporting a highly distributed energy future of this kind. Here a National Energy Programme would be responsible for delivering capacity for system balancing. A regulator 'OFGEM+' would have another arm or responsibility, operated through Regional Energy Partnerships (REP), to enable and regulate distributed energy from Local Energy Schemes and regulate local suppliers. 


\section{Conclusions}

This paper has investigated the feasibility, and implications, of high penetrations of distributed generation in Scotland. In doing so, the integrated energy system of Angus, a region in the East Coast of Scotland was represented using the HESA tool, developed by the authors for the analysis for multiple energy vector systems. The model of Angus used to investigate varying penetrations of DG in Scotland included the six major population centres in Angus and the transmission and transportation systems that connects them. The investigations of the system, in 2050, showed that that in order to minimise the curtailment of DG installations and maximise the utilisation of locally energy generated in a region it was essential that DG penetration is included in future network plans else curtailment and/or exports are high and utilisation low.

Simulations demonstrated that a future energy network that exists without the added capacity for the level of DG outlined in the Thousand Flowers Pathway, heavily constrain the possibility of exporting to the greater system and the revenue that such exports grant. Simulation results showed that with a constrained network system exports were only $17.5 \%$ of those of a non-constrained network with sufficient network capacity and that household revenue was curtailed to only $5 \%$ of the maximum capability.

In order to maximise the utilisation of locally generated energy local, regional or national electricity storage, alongside local, regional and national interconnection is a critical technology in system transition. If sufficient, reliable and local electrical storage is available regions could become electrically self-sufficient with capacity available to export excess thus creating local revenues and injecting money into the local economy. Alongside storage, installation of new heating technologies are essential along with distributed generation as Scotland's energy sector transitions to 2050. Emissions from natural gas fired heating systems were the main contributor to domestic emissions in the Angus region simulations. As such, it is important that technologies such as biomass fired heating units are considered to increase the percentage of renewable heat in Scotland and/or heat pumps to reduce local emissions.

This paper has identified that the different drivers, at different scales, for system change - whether that is to minimise environmental impacts, maximise revenues or minimise the reliance on external sources - dramatically changes system operation parameters and therefore planning concepts. For example, if the aim is to minimise the $\mathrm{CO}_{2}$ emissions of a region, i.e. a local driver impacted the local system, then the installation and utilisation of renewables would only be at a level to displace carbon intensive grid electricity demand. However, in the case of 
the Angus region modelled here, with an abundance of renewable resources as in most of Scotland, there is opportunity for higher rates of installation that would displace carbon intensive generation in other parts of the national system. Therefore, to best meet national targets, national drivers must permeate to all levels of system planning and be present to action change throughout the greater system. In the case of the installation of distributed generation, and other enabling technologies such as storage, for proper utilisation and to maximise benefits across multiple system aspects (finance, emissions etc.) alongside national frameworks, policies and drivers for change there must be regional frameworks of support, guidance or coordination to encourage, manage or perhaps itself determine and initiate system developments or change. Else, local solutions will only solve local issues and the difficulties faces by a greater national system will be unresolved.

New thinking and approaches to coordination and regulation of energy system transitions, like those considered in this paper, could see greater energy autonomy devolved to the regions and cities of the UK but within a framework that supports, and helps to meet, national objectives. The work of this paper has considered the case from the perspective of a single Scottish region however, further modelling and thinking is required to better understand the implications of a fully distributed UK energy system. 


\section{Funding statement or Declaration of conflicting interests}

This work was funded under the 'Realising Transition Pathways: whole systems analysis for a UK more electric low carbon energy future' project, supported by the UK Engineering and Physical Sciences Research Council (Grant Ref: EP/K005316/1).

\section{References}

1. Foxon TJ. Transition pathways for a UK low carbon electricity future. Energy Policy. 2013; 52: $10-24$

2. Barnacle M, Robertson E, Galloway S, Barton J and Ault G. Modelling generation and infrastructure requirements for transition pathways. Energy Policy. 2013; 52: 60-75.

3. Rudd A. Amber Rudd's speech on a new direction for UK energy policy. Department of Energy \& Climate Change 2015.

4. UK Government Climate Change Act. 2008.

5. The Scottish Government. 2020 Routemap for Renewable Energy in Scotland. 2011.

6. The Scottish Government. 2020 Routemap For Renewable Energy in Scotland - Update 2015. 2015.

7. Bergmann A, Hanley $\mathrm{N}$ and Wright R. Valuing the attributes of renewable energy investments. Energy Policy. 2006; 34: 1004-14.

8. Realising Transition Pathways. 2016.

9. Foxon TJ, Hammond GP and Pearson PJ. Transition pathways for a low carbon energy system in the U.K.: assessing the compatibility of large-scale and small-scale options 7th BIEE Academic Conference, St Johns College, Oxford. 2008.

10. Foxon DT, Hammond PG and Pearson PP. Transition pathways for a U.K. low carbon energy system: exploring different governance patterns. 1st European Conference on Sustainability Transitions. Amsterdam, The Netherlands2009.

11. Foxon TJ. Transition Pathways to a Low Carbon Economy: Conceptual and Analytical Framework. 2008.

12. Foxon TJ, Hammond GP and Pearson PJG. Developing transition pathways for a low carbon electricity system in the UK. Technological Forecasting and Social Change. 2010; 77: 1203-13.

13. Realising Transition Pathways Engine Room (RTP). Distributing Power: A transition to a civic energy future. Realising Transition Pathways Research Consortium. 2015.

14. Robertson EM, Alarcon-Rodriguez AD, Galloway SJ and Ault GW. Outline for an Integrated Multiple Energy Carrier Model of the U.K. Energy Infrastructure. 44th International Universities Power Engineering Conference. University of Strathclyde, Glasgow2009.

15. Robertson E, Galloway S and Ault G. The Impact of Wide Spread Adoption of High Levels of Distributed Generation in Domestic Properties. Power \& Energy Society General Meeting, 2012 PES '12 IEEE. 2012.

16. Bakken BH and Holen AT. Energy service systems: integrated planning case studies. Power Engineering Society General Meeting, 2004 IEEE. 2004, p. 2068-73 Vol.2.

17. Quelhas A, Gil E, McCalley JD and Ryan SM. A Multiperiod Generalized Network Flow Model of the U.S. Integrated Energy System: Part I-Model Description. Power Systems, IEEE Transactions on. 2007; 22: 829-36.

18. Quelhas A and McCalley JD. A Multiperiod Generalized Network Flow Model of the U.S. Integrated Energy System: Part II-Simulation Results. Power Systems, IEEE Transactions on. 2007; 22: 837-44.

19. Skarvelis-Kazakos S, Papadopoulos P, Grau Unda I, Gorman T, Belaidi A and Zigan S. Multiple energy carrier optimisation with intelligent agents. Applied Energy.

20. van Beuzekom I, Gibescu M and Slootweg JG. A review of multi-energy system planning and optimization tools for sustainable urban development. PowerTech, 2015 IEEE Eindhoven. 2015, p. 1-7. 
21. Bahrami S and Sheikhi A. From Demand Response in Smart Grid Toward Integrated Demand Response in Smart Energy Hub. Smart Grid, IEEE Transactions on. 2015; PP: 1-.

22. Bakken BH, Skjelbred $\mathrm{HI}$ and Wolfgang O. eTransport: Investment planning in energy supply systems with multiple energy carriers. Energy. 2007; 32: 1676-89.

23. Hammond GP and Stapleton AJ. Exergy analysis of the United Kingdom energy system. Proceedings of the Institution of Mechanical Engineers, Part A: Journal of Power and Energy. 2001; 215: 141-62.

24. Geidl M and Andersson G. Optimal Power Flow of Multiple Energy Carriers. Power Systems, IEEE Transactions on. 2007; 22: 145-55.

25. Pudjianto $D$, Ramsay $C$ and Strbac $G$. Virtual power plant and system integration of distributed energy resources. Renewable Power Generation, IET. 2007; 1: 10-6.

26. Pazouki S and Haghifam MR. The impacts of Virtual Power Plants on multiple carrier energy networks. Thermal Power Plants (CTPP), 2014 5th Conference on. 2014, p. 51-5.

27. Wang SJ, Shahidehpour SM, Kirschen DS, Mokhtari S and Irisarri GD. Short-term generation scheduling with transmission and environmental constraints using an augmented Lagrangian relaxation. Power Systems, IEEE Transactions on. 1995; 10: 1294-301.

28. Pretty JN, Ball AS, Lang T and Morison JIL. Farm costs and food miles: An assessment of the full cost of the UK weekly food basket. Food Policy. 2005; 30: 1-19.

29. Carradore $L$ and Bignucolo F. Distributed multi-generation and application of the energy hub concept in future networks. Universities Power Engineering Conference, 2008 UPEC 2008 43rd International. 2008, p. 1-5.

30. Hemmes K, Zachariah-Wolf JL, Geidl M and Andersson G. Towards multi-source multi-product energy systems. International Journal of Hydrogen Energy. 2007; 32: 1332-8.

31. Real AJd, Galus MD, Bordons C and Andersson G. Optimal Power Dispatch of Energy Networks including External Power Exchanges. European Control Conference. Budapest2009.

32. Department of Energy and Climate Change. 2050 Pathways Calculator. Available from: http://www.decc.gov.uk/en/content/cms/tackling/2050/calculator on/calculator on.aspx. 2011.

33. National Grid (GB Sytem Operator). 2009 Seven Year Statement. 2009.

34. National Grid (GB Sytem Operator). 2011 Ten Year Statement. 2012.

35. Department of Energy and Climate Change. 2050 Pathways Analysis. Available from: http://www.decc.gov.uk/en/content/cms/tackling/2050/2050.aspx. 2010.

36. General Register Office for Scotland. 2001 Census: Aggregate data (Scotland) UK Data Service Census Support,. Downloaded from: http://casweb.ukdataservice.ac.uk. This information is licensed under the terms of the Open Government Licence [http://www.nationalarchives.gov.uk/doc/opengovernment-licence/version/2].

37. Aggarwal SK, Saini LM and Kumar A. Electricity price forecasting in deregulated markets: A review and evaluation. International Journal of Electrical Power \& Energy Systems. 2009; 31: 13-22.

38. Strachan $\mathrm{N}$ and Kannan R. Hybrid modelling of long-term carbon reduction scenarios for the UK. Energy Economics. 2008; 30: 2947-63.

39. Kannan R and Strachan N. Modelling the UK residential energy sector under long-term decarbonisation scenarios: Comparison between energy systems and sectoral modelling approaches. Applied Energy. 2009; 86: 416-28.

40. OFGEM. Introducing the Feed-in Tariff scheme. 2010.

41. Realising Transition Pathways Engine Room. Distributing Power: A transition to a civic energy future. Realising Transition Pathways Research Consortium.2015. 